\title{
Thyroid Sonography as an Effective Tool to Discriminate between Euthyroid Sick and Hypothyroid Dogs
}

\author{
Sven Reese, Ulrike Breyer, Cornelia Deeg, Wilfried Kraft, and Bernd Kaspers
}

\begin{abstract}
The diagnosis of canine hypothyroidism and its differentiation from euthyroid sick syndrome still is a major diagnostic challenge. In this study, ultrasonography was shown to be an effective tool for the investigation of thyroid gland diseases. Healthy control dogs $(n=87)$, dogs with euthyroid sick syndrome $(n=26)$, thyroglobulin autoantibody-positive (TgAA-positive, $n=30)$ hypothyroid dogs, and TgAA-negative $(n=23)$ hypothyroid dogs were examined by thyroid ultrasonography. Maximal cross sectional area (MCSA), thyroid volume, and echogenicity were measured. Statistical analysis identified highly significant $(P<$ .001) differences between euthyroid and hypothyroid dogs both in thyroid volume and in MCSA, whereas no significant differences in thyroid size were detected between healthy euthyroid dogs and dogs with euthyroid sick syndrome. In euthyroid and euthyroid sick dogs, parenchymal echotexture was homogeneous and hyperechoic, whereas relative thyroid echogenicity of both TgAApositive and TgAA-negative hypothyroid dogs was significantly lower $(P<.001)$. When using arbitrarily chosen cutoff values for relative thyroid volume, MCSA, and echogenicity, thyroid volume especially was found to have highly specific predictive value for canine hypothyroidism. In summary, the data reveal that thyroid sonography is an effective ancillary diagnostic tool to differentiate between canine hypothyroidism and euthyroid sick syndrome.
\end{abstract}

Key words: Canine hypothyroidism; Euthyroid sick syndrome; Thyroglobulin autoantibodies; Thyroiditis; Ultrasound.

$\mathbf{H}$ pothyroidism is one of the most common endocrine disorders in dogs, ${ }^{1,2}$ but establishing the diagnosis can be a challenging task. ${ }^{3}$ Because of the widespread influences of thyroid hormones on cellular metabolism, clinical signs of hypothyroidism are quite variable and often vague, and they may resemble those of other disorders. Hypothyroidism can be associated with dermatological, neurological, reproductive, cardiovascular, hematological, and sometimes gastrointestinal signs. ${ }^{4-6}$

No single thyroid function test is completely reliable. ${ }^{3}$ Therefore, a combination of several findings is required including history, clinical signs, and results of thyroid gland function tests. Commonly used screening protocols for evaluating thyroid gland function include diagnostic tests for baseline tT4 or fT4, canine thyroid stimulating hormone (cTSH), and thyroglobulin autoantibody (TgAA) serum concentrations. ${ }^{2,7}$ All diagnostic tests may have false negative as well as false positive results and are affected by many variables..$^{2,7}$ Importantly, the euthyroid sick syndrome results in suppression of serum thyroid hormone concentrations in euthyroid dogs in response to concurrent illness. ${ }^{2,8}$ Furthermore, the administration of several drugs (eg, glucocorticoids, anticonvulsants, nonsteroidal anti-inflammatory drugs, furosemide, some antibiotics, and tricyclic antidepressants) can markedly affect thyroid function and results of thyroid function tests. ${ }^{9,10}$

Most canine hypothyroidism results from an atrophy of the thyroid gland caused by lymphocytic thyroiditis or idiopathic follicular atrophy. ${ }^{11,12}$ No diagnostic method yet

From the Institute of Veterinary Anatomy (Reese), Institute for Animal Physiology (Breyer, Deeg, Kaspers), and Clinic for Small Animal Internal Medicine (Breyer, Kraft), University of Munich, D-80539 Munich, Germany.

Reprint requests: Sven Reese, DVM, Institute of Veterinary Anatomy, Veterinärstrasse 13, 80539 München, Germany; e-mail: sven.reese@lmu.de.

Submitted April 6, 2004; Revised July 26, October 16, and November 25, 2004; Accepted February 14, 2005.

Copyright (C) 2005 by the American College of Veterinary Internal Medicine

0891-6640/05/1904-0001/\$3.00/0 has been established to measure these morphological changes in canine hypothyroidism.

In contrast, in humans thyroid sonography routinely is used for the detection of morphological changes in the thyroid gland. ${ }^{13-15}$ Determination of thyroid size and thyroid echogenicity have been well documented as useful and valid diagnostic findings in autoimmune thyroid disease and thyroid dysfunction. ${ }^{16-20}$ Diffuse reduction in thyroid echogenicity is a sign of an active cytotoxic autoimmune process $^{17}$ and is a valid predictor of autoimmune thyroiditis. ${ }^{16,18,21,22}$ Additionally, in humans a reduced thyroid volume is correlated with hypothyroidism. ${ }^{18,23,24}$

Although the technique of a sonographic examination of the canine thyroid gland was introduced several years ago, ${ }^{25}$ it has not yet been evaluated as a diagnostic tool in canine hypothyroidism. In the present study, the applicability of ultrasound in the diagnosis of canine hypothyroidism was investigated. In particular, sonographic variables were developed that allowed differentiation between hypothyroidism and euthyroid sick syndrome.

\section{Materials and Methods}

\section{Dogs}

Thirty TgAA-positive hypothyroid dogs, 23 TgAA-negative hypothyroid dogs, and 26 dogs with euthyroid sick syndrome (ESS) presented to the Clinic for Small Animal Internal Medicine at the University of Munich between 2000 and 2003 were included in this study. Dogs with secondary hypothyroidism (2 dogs) or primary hypothyroidism caused by neoplastic destruction of the thyroid gland ( 3 dogs) were excluded. Eighty-seven healthy dogs presented to the clinic for routine examination and vaccination served as controls (Table 1). Clinically healthy dogs with low tT4 $(<20 \mathrm{nM})$, low fT4 $(<10 \mathrm{pM})$, or a positive TgAA titer were excluded from the control group ( $8 \mathrm{dogs}$ ). Animals were cared for according to the principles of the German law on protection of animal welfare.

\section{Determination of Thyroid Status}

Dogs were grouped as euthyroid, TgAA-positive hypothyroid, TgAA-negative hypothyroid, or euthyroid sick according to clinical signs, results of physical examination, $\mathrm{CBC}$, serum biochemistry panel, and thyroid panel (tT4 $\left.{ }^{\mathrm{a}}, \mathrm{fT}^{\mathrm{a}} \mathrm{TSH}^{\mathrm{b}}, \mathrm{TgAA}^{\mathrm{c}}\right)$ as described. ${ }^{26-28} \mathrm{Cri}-$ 
Table 1. Group characteristic of the $166 \mathrm{dogs}$ in the study.

\begin{tabular}{lcccc}
\hline & & & \multicolumn{2}{c}{ TgAA-pos } \\
& Controls & $\begin{array}{c}\text { Euthyroid } \\
\text { Sick Dogs }\end{array}$ & $\begin{array}{c}\text { Typothyroid } \\
\text { Dogs }\end{array}$ & $\begin{array}{c}\text { Hypothyroid } \\
\text { Dogs }\end{array}$ \\
\hline Number & 87 & 26 & 30 & 23 \\
Age (years) & & & & \\
$\quad$ Median & 5 & 8 & 5 & 6.75 \\
$\quad$ Range & $1-14.5$ & $2-15$ & $2-13$ & $4-15$ \\
Weight (kg) & & & & \\
$\quad$ Median & 23 & 20 & 30 & 29.75 \\
Range & $2-76$ & $5.5-45$ & $6-72$ & $7-63$ \\
Sex & & & & \\
$\quad$ Male & 32 & 11 & 13 & 7 \\
$\quad$ Neutered male & 10 & 5 & 6 & 2 \\
Female & 19 & 4 & 7 & 4 \\
$\quad$ Spayed female & 26 & 6 & 4 & 10 \\
\hline
\end{tabular}

TgAA-pos, thyroglobulin autoantibody-positive; TgAA-neg, thyroglobulin autoantibody-negative.

teria for euthyroid status were (1) absence of clinical signs, (2) tT4 > $20 \mathrm{nM}$, (3) fT4 $>10 \mathrm{pM}$, (4) cTSH $<0.6 \mathrm{pg} / \mathrm{dL}$, and (5) negative TgAA titer. Hypothyroidism was confirmed by (1) thyrotropin releasing hormone (TRH) stimulation test, ${ }^{29,30}$ (2) a positive response to thyroid supplementation, or both. The TRH stimulation test was based on quantification of tT4 before, 2 hours after, and 4 hours after administration of $200 \mu \mathrm{g} \mathrm{TRH}{ }^{\mathrm{d}} \mathrm{IV}^{31}$ Hypothyroid dogs showed no increase of tT4 after TRH administration as compared with the normal value $(>20 \mathrm{nM})$. Dogs with low serum concentration of tT4 $(<20 \mathrm{nM})$, low fT4 $(<10 \mathrm{pM})$, or both caused by nonthyroidal illness were classified as euthyroid sick. ESS was confirmed by an increase in thyroid hormone concentrations to normal when concurrent illness had been eliminated.

\section{Sonography}

Ultrasonography of the thyroid gland was performed in a quiet room with minimal restraint of the dogs. None of the dogs was sedated for examination. All dogs were examined in a sitting position. A small area $(4 \times 4 \mathrm{~cm})$ caudal to the larynx was clipped, and coupling gel was applied. Sonographic examination of the thyroid glands was performed by 1 investigator (SR) with a $6-9 \mathrm{MHz}$ linear transducer ${ }^{\mathrm{e}}$ in large dogs $(>25 \mathrm{~kg})$ and a 7-13 MHz linear transducer in small dogs $(<25 \mathrm{~kg})$ by applying moderate probe pressure. At the time of sonographic examination, the sonographer did not know the category of the individual dogs.

Thyroid glands were scanned in longitudinal and transversal planes. The thyroid lobes were assessed by size, echogenicity, and homogeneity. To determine the volume of the thyroid lobes, the maximal length was measured in the longitudinal plane. In the next step, a transverse view of the thyroid gland was obtained by rotating the transducer 90 degrees and measuring the maximal width and height at the gland's maximum cross sectional area. Thyroid lobe volume was calculated by means of the ellipsoid formula ${ }^{32,33}$ :

$$
\operatorname{vol}(\mathrm{mL})=\pi / 6 \times \text { length }(\mathrm{cm}) \times \text { width }(\mathrm{cm}) \times \text { height }(\mathrm{cm}) .
$$

Total thyroid volume is given as the sum of left and right thyroid lobe volumes. In order to compare the quantitative variables among dogs of different sizes, thyroid volumes were related to metabolic body weight $\left(\mathrm{BW}^{0.75}\right) \cdot^{34}$ Additionally, the maximal cross sectional area (MCSA) of the thyroid lobes was measured as a second indicator of thyroid size. The MCSAs of both thyroid lobes were added and related to metabolic body weights. The reproducibility of the sonographic measurements was confirmed in 5 dogs that were examined 5 times. The value of the mean variation was $4.2 \%$.

Because echogenicity can be altered by adjusting instrument parameters such as gain setting, echogenicity of the thyroid gland was compared with the echogenicity of the adjacent sternothyroid muscle as a reference tissue (Fig 1). To determine the echogenicity, the mean density (MD) of the MCSA of the thyroid lobes and the MD of the cross sectional area of the adjacent sternothyroid muscle were measured by means of image analyzing software. ${ }^{f}$ Relative echogenicity of the thyroid gland was calculated by means of the formula

$$
\begin{aligned}
& \text { relative echogenicity } \\
& \quad=\mathrm{MD} \text { (thyroid gland)/MD (sternothyroid muscle). }
\end{aligned}
$$

Muscle echogenicity can vary with the animal's age or in relation to thyroid status. In this study, no statistically significant correlation was found between the echogenicity (MD) of the sternothyroid muscle and the age of the animals in the control group ( $\mathrm{r}$ [Spearman] $=0.08, P$ $=.452$ ). Likewise, when comparing the mean echogenicity of the sternothyroid muscles of the control dogs and that of the hypothyroid dogs no statistically significant difference was found (Mann-Whitney $U$-test, $P=.149$ ).

To determine the diagnostic value of sonography in canine hypothyroidism, sensitivity, specificity, and accuracy were calculated for the different sonographic variables as suggested by Ferguson et al. ${ }^{35}$ Sensitivity was defined as the fraction of dogs that actually were hypothyroid that were labeled as hypothyroid by sonography. Specificity was defined as the fraction of dogs that actually were euthyroid that were labeled as euthyroid by sonography. Accuracy was defined as the fraction of all dogs that were neither falsely positive nor falsely negative.

\section{Statistical Analysis}

Commercially available software ${ }^{\mathrm{g}}$ was used for statistical analysis. All values are presented as median and range. Differences among the 4 groups were analyzed by Mann-Whitney $U$-test. A $P$ value $<.05$ was considered significant.

\section{Results}

In each of the 166 dogs included in this study, both thyroid lobes were identified by sonography, and complete measurements were performed in all dogs (Table 2). All dogs were grouped by the criteria described in the "Material and Methods" section. Fifteen dogs were classified as ESS because of low serum concentration of tT4 $(<20$ $\mathrm{nM})$ and fT4 $(<10 \mathrm{pM})$, whereas in 9 ESS dogs fT4 concentrations were within the reference range. cTSH concentrations were within the reference range in 24 ESS dogs (92\%). In both ESS dogs with increased cTSH concentrations the hormone concentrations returned to the normal range within 2 months after successful treatment of the concurrent illness. In contrast, in the group of TgAA-positive hypothyroid dogs 4 dogs (13\%) had cTSH concentrations within the reference range, and in TgAA-negative hypothyroid dogs 11 dogs (48\%) had cTSH concentrations within the reference range. Complete results of endocrine testing of each group (tT4, fT4, cTSH) are presented in Fig 1a-c. In 36 of the hypothyroid dogs and in 11 of the ESS dogs, TRH stimulation tests were performed. All of these hypothyroid dogs failed to respond to TRH, but also in 5 of the ESS dogs no ( 2 dogs) or only a low ( 3 dogs) response to TRH was observed, and the 4-hour tT4 concentration was $<20 \mathrm{nM}$ (Table 3). Finally, in all dogs hypothyroidism was confirmed by a positive response to thyroxine treatment. 
a
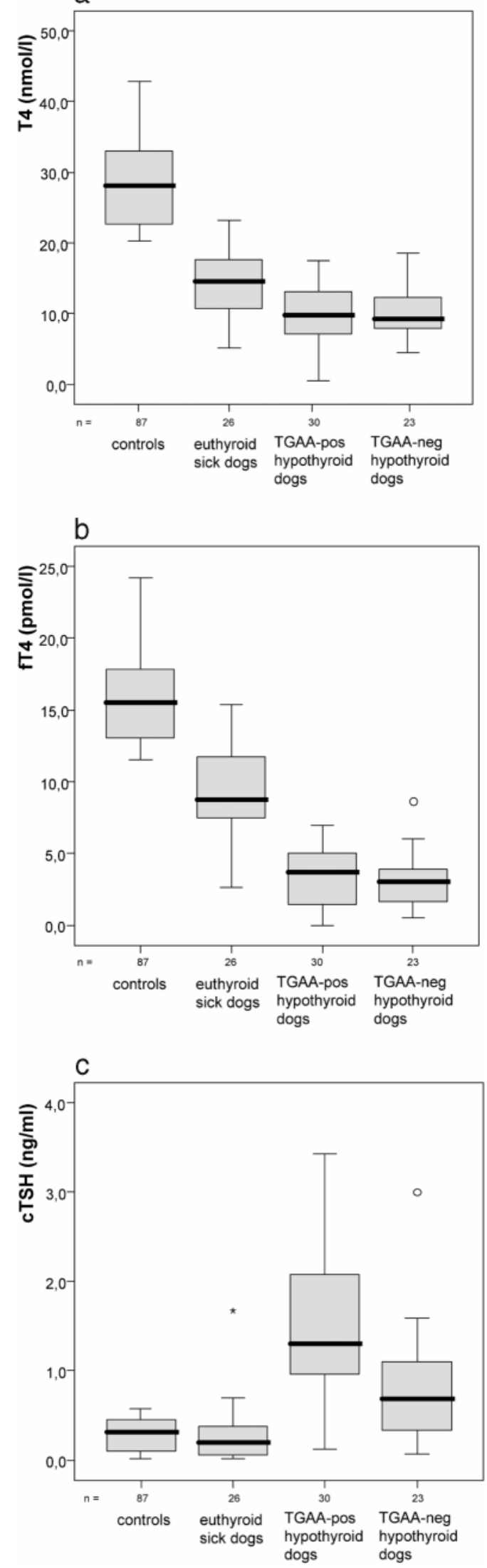

Table 2. Median and range of the thyroid volume, relative thyroid volume, relative thyroid cross sectional area, and relative echogenicity in the 4 groups of dogs with different functional thyroid status.

\begin{tabular}{|c|c|c|c|c|}
\hline & Controls & $\begin{array}{l}\text { Euthyroid } \\
\text { Sick Dogs }\end{array}$ & $\begin{array}{c}\text { TgAA-pos } \\
\text { Hypothyroid } \\
\text { Dogs }\end{array}$ & $\begin{array}{c}\text { TgAA-neg } \\
\text { Hypothyroid } \\
\text { Dogs }\end{array}$ \\
\hline \multicolumn{5}{|c|}{ Thyroid volume (ml) } \\
\hline $\begin{array}{l}\text { Median } \\
\text { Range }\end{array}$ & $\begin{array}{c}0.78 \\
0.08-2.2\end{array}$ & $\begin{array}{c}0.72 \\
0.21-1.52\end{array}$ & $\begin{array}{c}0.49 \\
0.08-1.22\end{array}$ & $\begin{array}{c}0.47 \\
0.10-1.02\end{array}$ \\
\hline \multicolumn{5}{|c|}{ Relative thyroid volume $\left(\mathrm{ml} / \mathrm{kg}^{0.75}\right)$} \\
\hline $\begin{array}{l}\text { Median } \\
\text { Range }\end{array}$ & $\begin{array}{c}0.08 \\
0.03-0.13\end{array}$ & $\begin{array}{c}0.07 \\
0.04-0.12\end{array}$ & $\begin{array}{c}0.04 \\
0.01-0.12\end{array}$ & $\begin{array}{c}0.04 \\
0.01-0.07\end{array}$ \\
\hline \multicolumn{5}{|c|}{ Relative thyroid cross sectional area $\left(\mathrm{mm}^{2} / \mathrm{kg}^{0.75}\right)$} \\
\hline $\begin{array}{l}\text { Median } \\
\text { Range }\end{array}$ & $\begin{array}{c}4.77 \\
2.66-7.89\end{array}$ & $\begin{array}{c}4.57 \\
2.87-7.16\end{array}$ & $\begin{array}{c}2.45 \\
1.08-7.39\end{array}$ & $\begin{array}{c}2.63 \\
1.18-5.01\end{array}$ \\
\hline \multicolumn{5}{|c|}{ Relative echogenicity } \\
\hline $\begin{array}{l}\text { Median } \\
\text { Range }\end{array}$ & $\begin{array}{c}1.57 \\
1.09-2.68\end{array}$ & $\begin{array}{c}1.77 \\
1.24-2.81\end{array}$ & $\begin{array}{c}1.18 \\
0.66-1.83\end{array}$ & $\begin{array}{c}1.23 \\
0.81-2.81\end{array}$ \\
\hline
\end{tabular}

TgAA-pos, thyroglobulin autoantibody-positive; TgAA-neg, thyroglobulin autoantibody-negative.

Generally, the shape and MCSA of the thyroid lobes were different in euthyroid and ESS dogs as compared with both groups of hypothyroid dogs. In the majority of euthyroid and ESS dogs, the MCSA was triangular or polygonal (Fig 2), whereas the MCSA was oval in most hypothyroid dogs. In the longitudinal plane, the thyroid lobes were spindle shaped in all dogs of the 4 groups (Fig 3a-c).

Significant $(P<.001)$ differences in the thyroid volume as well as in the MCSA were found between euthyroid dogs and hypothyroid dogs (Fig 4a), whereas no significant differences in thyroid size were detected between healthy euthyroid dogs and dogs with ESS. When comparing TgAApositive and TgAA-negative hypothyroid dogs, no significant differences in thyroid size were identified (Fig 4a).

In euthyroid and ESS, thyroid parenchymal echotexture was homogeneous and hyperechoic as compared with the adjacent sternothyroid muscle (Figs 2, 3a). In contrast, the relative thyroid echogenicity of both TgAA-positive and TgAA-negative hypothyroid dogs was significantly lower $(P<.001)$ as compared with euthyroid dogs (Fig 4c). In TgAA-positive hypothyroid dogs, thyroid echotexture was homogenously hypoechoic (Fig 3b), whereas the thyroid parenchyma in $10 \mathrm{TgAA}$-negative hypothyroid dogs showed a heterogeneous echotexture. In these dogs echotexture was characterized by a dark background interrupted by hyperechoic spots and lines (Fig 3c).

$\leftarrow$

Fig 1. (a) Median and range of tT4 serum concentrations in euthyroid, euthyroid sick, thyroglobulin autoantibody-positive (TgAA-positive), and TgAA-negative hypothyroid dogs. (b) Median and range of fT4 serum concentrations in euthyroid, euthyroid sick, TgAA-positive, and TgAA-negative hypothyroid dogs. (c) Median and range of canine thyroid stimulating hormone serum concentrations in euthyroid, euthyroid sick, TgAA-positive, and TgAA-negative hypothyroid dogs. 
Table 3. Median and range of tT4 serum concentrations before as well as 2 and 4 hours after administration of 200 $\mu \mathrm{g}$ TRH IV in 36 hypothyroid dogs and 11 euthyroid sick dogs.

\begin{tabular}{|c|c|c|c|}
\hline & $\begin{array}{l}\text { tT4 }(\mathrm{nM}) \\
\text { Pre-TRH }\end{array}$ & $\begin{array}{c}\mathrm{tT} 4(\mathrm{nM}) \\
2 \text { Hours } \\
\text { Post-TRH }\end{array}$ & $\begin{array}{c}\text { tT4 }(\mathrm{nM}) \\
4 \text { Hours } \\
\text { Post-TRH }\end{array}$ \\
\hline \multicolumn{4}{|c|}{ Hypothyroid dogs } \\
\hline $\begin{array}{l}\text { Median } \\
\text { Range }\end{array}$ & $\begin{array}{c}9.93 \\
1.53-19.1\end{array}$ & $\begin{array}{c}10.64 \\
1.59-20.1\end{array}$ & $\begin{array}{c}10.28 \\
1.54-19.4\end{array}$ \\
\hline \multicolumn{4}{|c|}{ Euthyroid sick dogs } \\
\hline $\begin{array}{l}\text { Median } \\
\text { Range }\end{array}$ & $\begin{array}{c}14.37 \\
6.83-16.85 \\
\end{array}$ & $\begin{array}{c}17.46 \\
6.94-20.27 \\
\end{array}$ & $\begin{array}{c}20.54 \\
6.88-24.51 \\
\end{array}$ \\
\hline
\end{tabular}

TRH, thyrotropin releasing hormone.

In order to further analyze the predictive value of ultrasound variables, cutoff values were chosen by trial and error to maximize sensitivity and specificity. The cutoff values were $0.05 \mathrm{~mL} / \mathrm{kg}^{0.75}$ for relative thyroid volume, 3.3 $\mathrm{mm}^{2} / \mathrm{kg}^{0.75}$ for relative thyroid cross sectional area, and 1.4 for relative echogenicity. When a cutoff value for relative thyroid volume $<0.05 \mathrm{~mL} / \mathrm{kg}^{0.75}$ was used, sonography indicated hypothyroidism with a sensitivity of $81 \%$, specificity of $96 \%$, and accuracy of $91 \%$ (Table 4). With the relative thyroid cross sectional area with a cutoff value $<3.3$ $\mathrm{mm}^{2} / \mathrm{kg}^{0.75}$, the sensitivity was slightly reduced (77\%), whereas specificity $(96 \%)$ and accuracy $(90 \%)$ were found to be comparably high. If a cutoff value of $<1.4$ for the relative echogenicity was used, the sensitivity for the detection of hypothyroidism was $75 \%$, with a specificity of $80 \%$ and an accuracy of $78 \%$. The highest sensitivity for the detection of hypothyroidism was found when a combination of relative thyroid volume and relative echogenicity was used. In this situation, hypothyroidism was predicted with a sensitivity of $98 \%$ if one or both of these variables were below the chosen cutoff values.

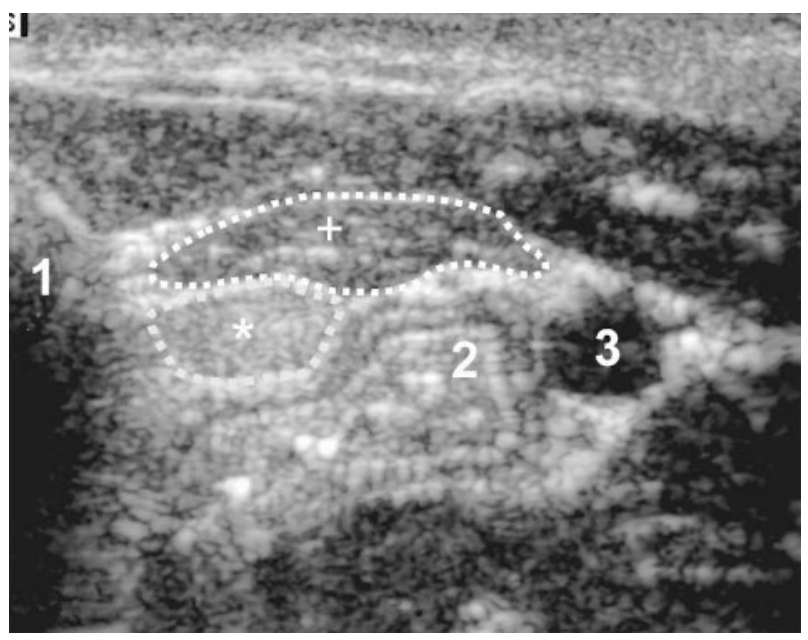

Fig 2. Transversal plane of the left thyroid lobe in a euthyroid male beagle. The maximal cross sectional area (MCSA) of the thyroid gland $(*)$ and of the sternothyroid muscle $(+)$ were marked by dotted lines. 1, trachea; 2, esophagus; 3 , left common carotid artery. a

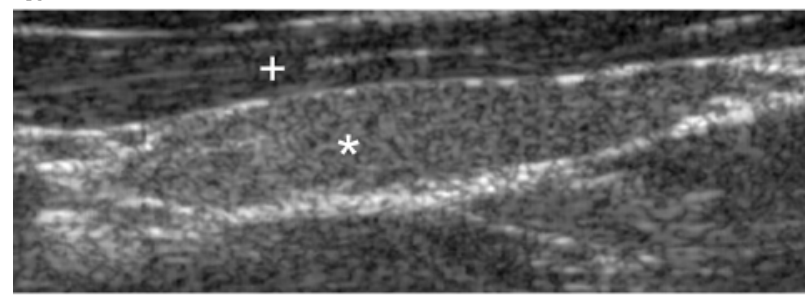

b

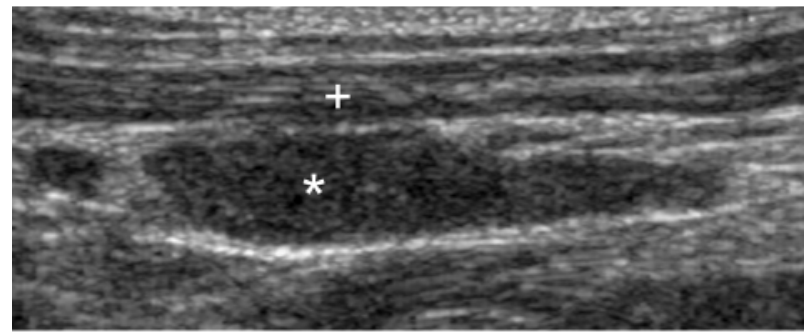

C

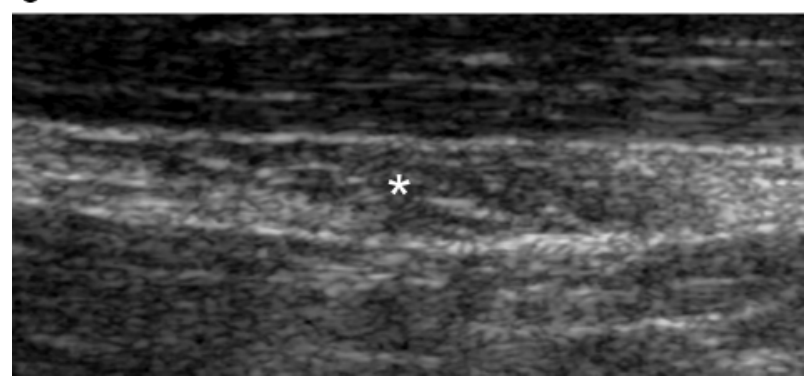

Fig 3. (a) Longitudinal section of the right thyroid lobe in a euthyroid dog. The echotexture of the thyroid gland $(*)$ was hyperechoic in comparison with the adjacent sternothyroid muscle $(+)$. (b) Longitudinal section of the left thyroid lobe in a thyroglobulin autoantibodypositive (TgAA-positive) hypothyroid dog. The echotexture of the thyroid gland $(*)$ was hypoechoic in comparison with the adjacent sternothyroid muscle $(+)$. (c) Longitudinal section of the left thyroid gland (*) in a TgAA-negative hypothyroid dog. The echotexture of the thyroid gland was heterogeneous with a hypoechoic background interrupted by hyperechoic lines and spots.

\section{Discussion}

Hypothyroidism is one of the most common endocrine diseases in dogs. Its diagnosis and differentiation between hypothyroidism and ESS still represent a major diagnostic challenge in dogs with low serum thyroid hormone concentrations. ${ }^{2,3}$ For example, the TRH stimulation test, which was used in place of the TSH stimulation test because of limited availability of TSH, was unsuitable to differentiate between ESS dogs and hypothyroid dogs. Although clinical and laboratory variables have been evaluated extensively as diagnostic tools, sonography has not been routinely used in this disease. This is the first report demonstrating that sonography is an effective diagnostic procedure that specifically enables discrimination between hypothyroidism and ESS in dogs.

Although earlier reports demonstrated that diagnostic ultrasound is an excellent method for the evaluation of canine thyroid gland size, ${ }^{36}$ examination of the thyroid gland by 
a

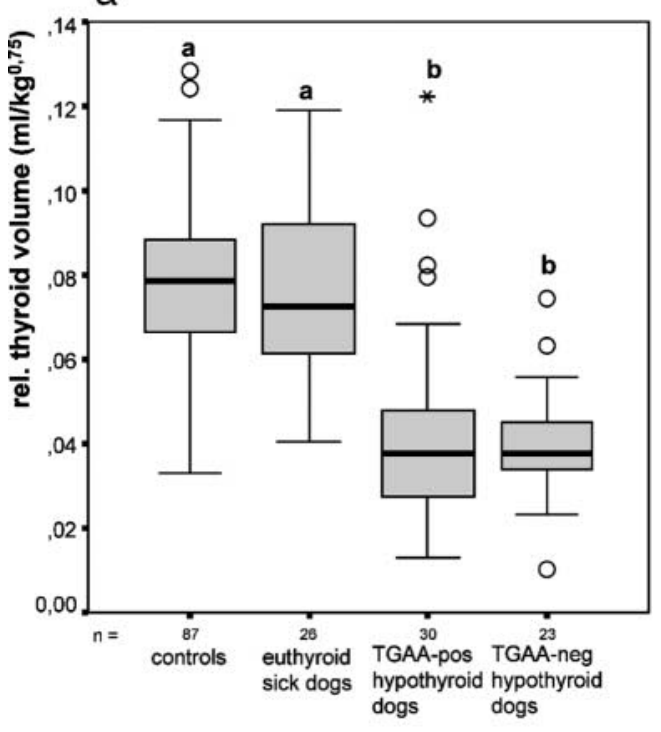

b
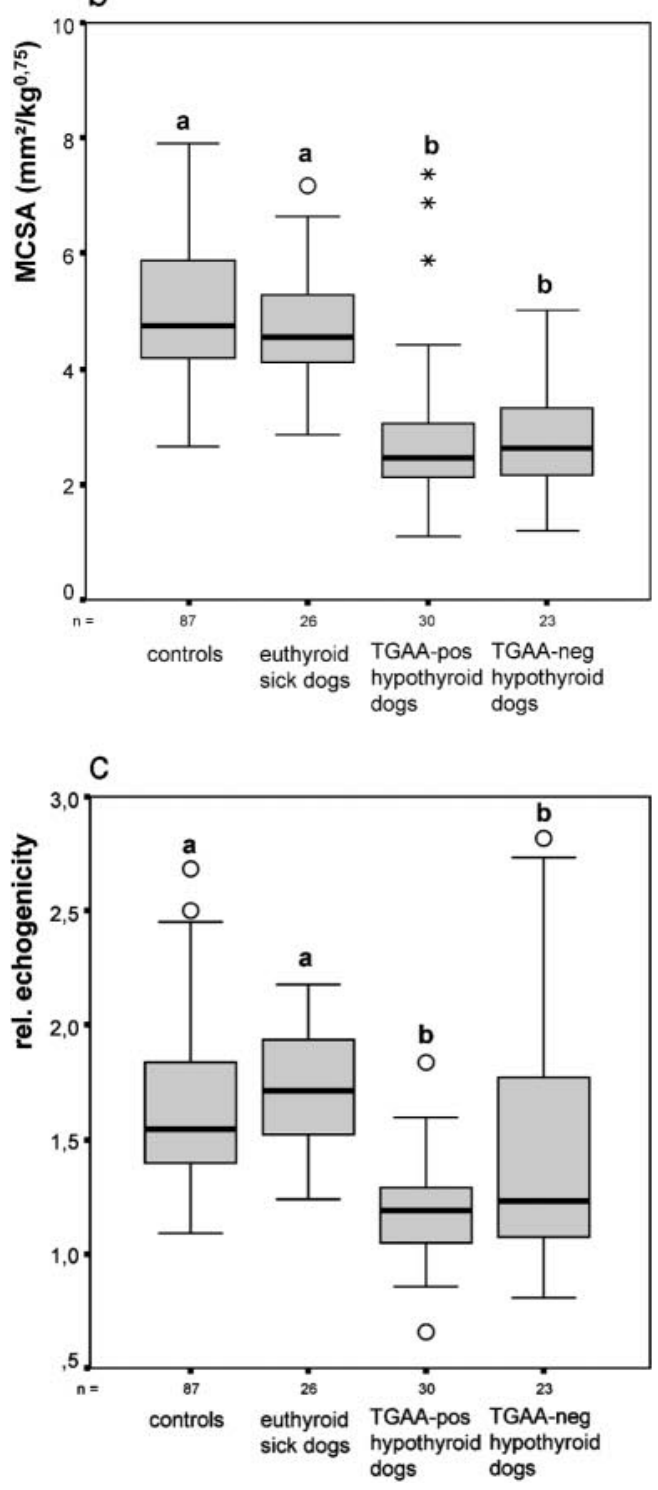

sonography in canine hypothyroidism has not yet been documented in the literature. First, this can be explained by the fact that no reference data on the thyroid size in healthy dogs are available. Secondly, the large range of thyroid size in dogs of different body weights makes it difficult to compare quantitative data among different breeds. To overcome these problems, thyroid sizes were compared by relating them to BW ${ }^{0.75}$. Both thyroid volume and MCSA were used as indicators of thyroid size in this study. Calculation of thyroid volume by the ellipsoid method (as applied in this study) is a well-established technique, ${ }^{32,33,37,38}$ but requires accurate sonographic technique and measurements to minimize interobserver variability ${ }^{39}$ To address these problems, measurements were obtained by 1 single investigator (SR) in this study. However, results obtained with different ultrasonographers may be different. In future studies, the interobserver variability should be investigated. An additional possible error in calculation of the volume is the underestimation of the organ length due to difficulty in imaging the entire thyroid gland in the long axis scan plane. ${ }^{33} \mathrm{In}$ contrast, measurement of the MCSA in the short axis plane is easy to perform and does not require additional calculation. With this technique, false data only will be obtained if an oblique scan plane is taken for measurement as previously reported for adrenal gland sonography. ${ }^{40}$ Another possible source of error in calculating thyroid volume by means of a formula for an ellipsoid object is the variability in the cross sectional profile of the thyroid gland. However, former studies revealed a high correlation between the real volume of canine thyroid gland and the volumes calculated by the ellipsoid method..$^{34}$ In the present study, the relative thyroid volume and the relative MCSA were found to be significantly $(P<.001)$ lower in hypothyroid dogs as compared with euthyroid and ESS dogs. These results correlate with studies in humans that describe significantly reduced thyroid volumes in patients with hypothyroidism. ${ }^{18,23,24} \mathrm{Im}$ portantly, no differences were seen between euthyroid and ESS dogs. Therefore, ultrasonographic analysis of thyroid volume or MCSA allows differentiation between ESS and hypothyroid dogs.

To calculate the diagnostic value (ie, specificity, sensitivity, accuracy) of these thyroid variables, optimal cutoff values for thyroid volume and MCSA were determined. Relative thyroid volume and relative MCSA revealed high specificity (96\%) and accuracy (91 and 90\%), whereas sensitivity was found to be lower (81 and $77 \%$ ). Therefore, both variables for thyroid size are excellently suited to con-

$\leftarrow$

Fig 4. (a) Median and range of relative thyroid volume in euthyroid, euthyroid sick, thyroglobulin autoantibody-positive (TgAA-positive), and TgAA-negative hypothyroid dogs. Significant differences between medians are indicated by different superscripts $(P<.05)$. (b) Median and range of relative maximal cross sectional area in euthyroid, euthyroid sick, TgAA-positive, and TgAA-negative hypothyroid dogs. Significant differences between medians are indicated by different superscripts $(P<.05)$. (c) Median and range of relative echogenicity in euthyroid, euthyroid sick, TgAA-positive, and TgAA-negative hypothyroid dogs. Significant differences between medians are indicated by different superscripts $(P<.05)$. 
Table 4. Sensitivity, specificity, and accuracy of cutoff relative thyroid volume value $\left(<0.05 \mathrm{ml} / \mathrm{kg}^{0.75}\right)$, relative thyroid maximal cross sectional area (MCSA) value $\left(<3.3 \mathrm{~mm}^{2} / \mathrm{kg}^{0.75}\right)$, and relative echogenicity value $(<1.4)$ for detection of canine hypothyroidism.

\begin{tabular}{|c|c|c|c|c|c|}
\hline & $\begin{array}{c}\text { Relative Thyroid } \\
\text { Volume }\end{array}$ & $\begin{array}{l}\text { Relative Cross } \\
\text { Sectional Area }\end{array}$ & $\begin{array}{c}\text { Relative } \\
\text { Echogenicity }\end{array}$ & $\begin{array}{l}\text { Low Relative } \\
\text { Volume or } \\
\text { Low Relative } \\
\text { Echogenicity }\end{array}$ & $\begin{array}{c}\text { Low MCSA } \\
\text { or Low Relative } \\
\text { Echogenicity }\end{array}$ \\
\hline Sensitivity (\%) & 81 & 77 & 75 & 98 & 94 \\
\hline Specificity (\%) & 96 & 96 & 80 & 77 & 77 \\
\hline Accuracy $(\%)$ & 91 & 90 & 78 & 84 & 83 \\
\hline
\end{tabular}

firm canine hypothyroidism. The diagnostic value of these thyroid variables is comparable to that of laboratory testing revealing low tT4 or fT4 by dialysis in combination with a high TSH concentration, which was reported to lead to the diagnosis of hypothyroidism in most dogs. ${ }^{26,27}$

Besides atrophy of the thyroid gland, the second most common pathological finding in canine hypothyroidism is atrophic autoimmune thyroiditis. ${ }^{12}$ In humans, determination of thyroid echogenicity has been well documented as a valid diagnostic test for the detection of autoimmune thyroiditis. ${ }^{16-20}$ Autoimmune thyroiditis sonographically is characterized by a hypoechoic echotexture of the thyroid parenchyma. ${ }^{16-22}$ Because this variable has not been evaluated in dogs, we sought to investigate changes in thyroid gland echogenicity in canine hypothyroidism.

Changes in echogenicity often are subtle, and differences in echo pattern may be difficult to detect. Furthermore, echogenicity can be altered by adjusting parameters such as gain setting. Therefore, perception of image density by the naked eye is unreliable. ${ }^{41}$ Two different methods generally are used to evaluate image density in an objective way. First, thyroid echogenicity can be characterized by standardized ultrasonography under defined operating conditions. ${ }^{20,42}$ However, standardized ultrasonography is difficult to achieve under practical conditions. Therefore, comparison of the echogenicity of the target structure with a reference tissue with the same conditions in 1 scan proved to be more useful in practical terms. ${ }^{21}$ In humans, relative echogenicity of the thyroid gland when compared with sternothyroid muscle was found to be useful to differentiate a healthy thyroid gland from a gland with thyroiditis. ${ }^{21}$ In dogs, the sternothyroid muscle (which lies near the thyroid gland) proved to be a more reliable tissue for comparison.

The results revealed that the relative echogenicity of the thyroid gland parenchyma was significantly $(P<.001)$ lower in hypothyroid dogs as compared with euthyroid and ESS dogs. These results correlate with findings in humans in whom marked hypoechogenicity of the thyroid gland implies an active autoimmune process and possibly a hypothyroid state. ${ }^{17,19,22}$ Interestingly, in 10 out of 23 TgAAnegative hypothyroid dogs an isoechoic or hyperechoic echotexture of the thyroid gland was found. In these dogs the echotexture was heterogeneous. We propose that this echotexture may reflect replacement of the thyroid tissue by fibrous and adipose tissue as described in dogs with noninflammatory atrophic hypothyroidism. ${ }^{43}$ In humans, a similar echotexture was described in the end stages of lymphocytic thyroiditis. ${ }^{44}$ Therefore, these observations further support the hypothesis that antibody-negative canine hypothyroidism represents a late stage of autoimmune thyroiditis. ${ }^{12,45-47}$

The variability in echotexture and echogenicity in thyroid glands of hypothyroid animals results in lower sensitivity, specificity, and accuracy of thyroid echogenicity as a diagnostic variable as compared with the thyroid size. Nevertheless, the results indicate that echogenicity may prove to be an effective variable for the detection of subclinical stages of canine hypothyroidism. When combining variables (relative thyroid volume and relative thyroid echogenicity) sonography is an excellent screening method with a high sensitivity (98\%) for canine hypothyroidism. A comparable value is only achieved with the detection of low fT4 concentrations by the expensive and time-consuming equilibrium dialysis technique. ${ }^{35}$

In conclusion, thyroid sonography enabled us to establish a diagnosis in dogs with decreased thyroid hormone concentrations of unknown etiology. It is a reliable diagnostic tool to differentiate between canine hypothyroidism and ESS and an effective complement to established routine diagnostic tests. Thus, sonography facilitates the interpretation of laboratory test results by avoiding the erroneous diagnosis of canine hypothyroidism and resulting unwarranted treatment.

\section{Footnotes}

${ }^{\text {a }}$ Chemiluminescence Assay Elecys 1010 (previously validated for the $\operatorname{dog}^{48}$ ), Boehringer Mannheim Labdiagnostics, Mannheim, Germany

${ }^{\mathrm{b}}$ cTSH-enzyme linked immunosorbent assay (previously validated for the $\operatorname{dog}^{49}$ ), Milenia Biotec GmbH, Bad Nauheim, Germany

${ }^{c}$ Enzyme linked immunosorbent assay, in house test previously validated for the $\operatorname{dog}^{50,51}$

d TRH-Ferring, Kiel, Germany

${ }^{\mathrm{e}}$ Siemens Sonoline Elegra ultrasound unit, Siemens AG, Erlangen, Germany

${ }^{\mathrm{f}}$ Scion Image for Windows 4.02, Scion Corporation, Frederick, MD

${ }^{g}$ SPSS 11.5.1, SPSS Inc, Chicago, IL

\section{Acknowledgment}

This study was supported by a grant from the "Gesellschaft zur Förderung der Kynologischen Forschung", (GKF), Bonn, Germany. 


\section{References}

1. Scarlett JM. Epidemiology of thyroid diseases of dogs and cats. Vet Clin North Am Small Anim Pract 1994;24:477-486.

2. Nelson RW, Couto CG. Small Animal Internal Medicine, 3rd ed. St Louis, MO: Mosby Int; 2003:691-710.

3. Panciera DL. Is it possible to diagnose canine hypothyroidism? J Small Anim Pract 1999;40:152-157.

4. Jaggy A, Oliver JE, Ferguson DC, et al. Neurological manifestations of hypothyroidism: A retrospective study of 29 dogs. J Vet Intern Med 1994;8:328-336.

5. Panciera DL. Conditions associated with canine hypothyroidism. Vet Clin North Am Small Anim Pract 2001;31:935-950.

6. Boretti FS, Breyer-Haube I, Kaspers B, Reusch CE. Klinische, häematologische, biochemische und endokrinologische Aspekte bei 32 Hunden mit Hypothyreose. "Clinical, haematological, biochemical and endocrinological aspects of canine hypothyroidism in Switzerland." Schweiz Arch Tierheilkd 2003;145:149-159.

7. Kemppainen RJ, Behrend EN. Diagnosis of canine hypothyroidism. Vet Clin North Am Small Anim Pract 2001;31:951-962.

8. Panciera DL, Ritchey JW, Ward DL. Endotoxin-induced nonthyroidal illness in dogs. Am J Vet Res 2003;64:229-234.

9. Daminet S, Ferguson DC. Influence of drugs on thyroid function in dogs. J Vet Intern Med 2003;17:463-472.

10. Gulikers KP, Panciera DL. Influence of various medications on canine thyroid function. Comp Contin Educ Pract Vet 2002;24:511523.

11. Gosselin SJ, Capen CC, Martin SL. Histologic and ultrastructural evaluation of thyroid lesions associated with hypothyroidism in dogs. Vet Pathol 1981;18:299-309.

12. Graham PA, Nachreiner RF, Refsal KR, et al. Lymphocytic thyroiditis. Vet Clin North Am Small Anim Pract 2001;31:915-933.

13. Khati N, Adamson T, Johnson KS, Hill MC. Ultrasound of the thyroid and parathyroid glands. Ultrasound Q 2003;19:162-176.

14. Lee HK, Hur MH, Ahn SM. Diagnosis of occult thyroid carcinoma by ultrasonography. Yonsei Med J 2003;44:1040-1044.

15. Kouvaraki MA, Shapiro SE, Fornage BD, et al. Role of preoperative ultrasonography in the surgical management of patients with thyroid cancer. Surgery 2003;134:946-954.

16. Pederson OM, Aardal NP, Larssen TB, et al. The value of ultrasonography in predicting autoimmune thyroid disease. Thyroid 2000;10:251-259.

17. Lai SM, Chang TC, Chang CC, et al. Sonographic presentation in autoimmune thyroiditis. J Formos Med Assoc 1990;89:1057-1062.

18. Vitti P, Lampis M, Piga M, et al. Diagnostic usefulness of thyroid ultrasonography in atrophic thyroiditis. J Clin Ultrasound 1994; 22:375-379.

19. Marcocci C, Vitti P, Cetani F, et al. Thyroid ultrasonography helps to identify patients with diffuse lymphocytic thyroiditis who are prone to develop hypothyroidism. J Clin Endocrinol Metab 1991;71: 209-213.

20. Schiemann U, Gellner R, Riemann B, et al. Standardized grey scale ultrasonography in Graves' disease: Correlation to autoimmune activity. Eur J Endocrinol 1999;141:332-336.

21. Ying M, Phil M, Brook F, et al. The value of thyroid parenchymal echogenicity as an indicator of pathology using the sternomastoid muscle for comparison. Ultrasound Med Biol 1998;24:10971105.

22. Hayashi N, Tamaki N, Konishi J, et al. Sonography of Hashimoto's thyroiditis. J Clin Ultrasound 1986;14:123-126.

23. Rieu M, Portos C, Lissak B, et al. Relationship of antibodies to thyrotropin receptors and to thyroid ultrasonographic volume in euthyroid and hypothyroid patients with autoimmune thyroiditis. J Clin Endocrinol Metab 1996;81:641-645.

24. Nordmeyer JP, Shafeh TA, Heckmann C. Thyroid sonography in autoimmune thyroiditis. A prospective study on 123 patients. Acta Endocrinol 1990;122:391-395.
25. Wisner ER, Mattoon JS, Nyland TG, Baker TW. Normal ultrasonographic anatomy of the canine neck. Vet Radiol 1991;32:185-190.

26. Peterson ME, Melian C, Nichols R. Measurement of serum total thyroxine, triiodthyronine, free thyroxine, and thyrotropin concentrations for diagnosis of hypothyroidism in dogs. J Am Vet Med Assoc 1997;211:1396-1402.

27. Dixon RM, Mooney CT. Evaluation of serum free thyroxine and thyrotropin concentrations in the diagnosis of canine hypothyroidism. J Small Anim Pract 1999;40:72-78.

28. Dixon RM, Mooney CT. Canine serum autoantibodies in health, hypothyroidism, and non-thyroidal illness. Res Vet Sci 1999;66:243246.

29. Ramsey IK, Evans H, Herrtage ME. Thyroid-stimulating hormone and total thyroxine concentrations in euthyroid, sick euthyroid and hypothyroid dogs. J Small Anim Pract 1997;38:540-545.

30. Scott-Moncrieff JCR, Nelson RW. Change in serum thyroidstimulating hormone concentration in response to administration of thyrotropin-releasing hormone to healthy dogs, hypothyroid dogs, and euthyroid dogs with concurrent disease. J Am Vet Med Assoc 1998; 10:1435-1438.

31. Kraft W, Burckhardt A. Untersuchungen zum Thyreotropin-Releasing-Hormon-(TRH) Test beim Hund. "Investigations into the thyrotropin-releasing-hormone (TRH) test in the dog." Tierarztl Prax 1994;22:159-164.

32. Chanoine JP, Toppet V, Lagasse R, et al. Determination of thyroid volume by ultrasound from the neonatal period to late adolescence. Eur J Pediatr 1991;150;395-399.

33. Wisner ER, Théon AP, Nyland TG, Hornof WJ. Ultrasonographic examination of the thyroid gland of hyperthyroid cats: Comparison to ${ }^{99 \mathrm{~m}} \mathrm{TcO}_{4}^{-}$scintigraphy. Vet Radiol Ultrasound 1994;35:5358.

34. Reese S. Schilddrüsensonographie bei Hund und Katze-Eine angewandt anatomische Studie. "Ultrasonographic Examination of the Feline and Canine Thyroid Gland-An Applied Anatomical Study." Munich: University of Munich; 2002. Thesis (Habilitationsschrift).

35. Ferguson D, Graham P, Kintzer P, et al. Thyroid function tests in the dog: SCE consensus refined and defined. Proc 21st Amer Coll Vet Intern Med Forum, Charlotte, NC, June 4-7, 2003.

36. Wisner ER, Mattoon JS, Nyland TG. Neck. In: Nyland JS, Mattoon JS, ed. Small Animal Diagnostic Ultrasound, 2nd ed. Philadelphia, PA: WB Saunders; 2002:285-304.

37. Nelson M, Wickus GG, Caplan RH, Beguin EA. Thyroid gland size in pregnancy. An ultrasound and clinical study. J Reprod Med $1987 ; 32: 888-890$.

38. Rendl J, Juhran N, Reiners Chr. Thyroid volumes and urinary iodine in German school children. Exp Clin Endocrinol Diabetes 2001; 109:8-12.

39. Gönci J, Szabolcs I, Magyar E. Ultrasound volumetry of the thyroid. Aktuelle Radiol 1993;3:283-285.

40. Nyland TG, Mattoon JS, Herrgesell EJ, Wisner ER. Adrenal glands. In: Nyland JS, Mattoon JS, ed. Small Animal Diagnostic Ultrasound, 2nd ed. Philadelphia, PA: WB Saunders; 2002;196-206.

41. Blickstein I, Goldman R. The relation between different system gain settings and the accuracy of densitometric assessment of echogenicity. J Ultrasound Med 1994;13:675-678.

42. Schiemann U, Avenhaus W, Konturek JW, et al. Relationship of clinical features and laboratory parameters to thyroid echogenicity measured by standardized grey scale ultrasonography in patients with Hashimoto's thyroiditis. Med Sci Monit 2003;9:13-17.

43. Conaway DH, Padgett GA, Bunton TE, et al. Clinical and histological features of primary progressive, familial thyroiditis in a colony of borzoi dogs. Vet Pathol 1985;22:439-446.

44. Saleh A, Santen R, Malms J, et al. B-Mode-Sonographie und moderne dopplersonographische Methoden bei Krankheiten der Schilddrüse und Nebenschilddrüsen. "B-Mode sonography and mod- 
ern dopplersonographic methods in diseases of the thyroid and parathyroid glands." Radiologe 1998;38:344-354.

45. Beale K, Halliwell RE, Chen CL. Prevalence of antithyroglobulin antibodies detected by enzyme-linked immunosorbent assay of canine serum. J Am Vet Med Assoc 1990;196:745-748.

46. Thacker EL, Refsal KR, Bull RW. Prevalence of autoantibodies to thyroglobulin, thyroxine, or triiodthyronine and relationship of autoantibodies and serum concentrations of iodothyronines in dogs. Am J Vet Res 1992;53:449-453.

47. Vollset I, Larsen HJ. Occurrence of autoantibodies against thyroglobulin in Norwegian dogs. Acta Vet Scand 1987;28:65-71.

48. Lammerer SH. Validierung eines Chemilumineszenzenzymimmunoassays und Elektrochemilumineszenzimmunoassays für die Hor- mone tT4, fT4, tT3, fT3, Kortisol, Insulin und Digoxin beim Hund. Munich, Germany: University of Munich; 2003. Thesis.

49. Ruschig S, Kraft W. Determination of canine thyroid stimulating hormone (cTSH) in blood serum of dogs and its reaction to the TRH-stimulation test. Tierarztl Prax 1996;24:479-483.

50. Deeg C, Kaspers A, Hartmann K, et al. Canine Hypothyreose: Nachweis von Autoantikörpern gegen Thyreoglobulin. "Hypothyroidism in dogs: Detecting autoantibody to thyroglobulin." Tierarztl Prax 1997;25:170-173.

51. Haube U. Thyreoglobulinspezifische Autoantikörper beim Hund. Nachweis und Prävalenz. "Thyroglobulin autoantibodies in the dog. Detection and prevalence.” Munich, Germany: University of Munich; 1999. Thesis. 